\title{
The Efficacy of Solifenacin Added to A-Adrenergic Antagonists in the Treatment of Lower Urinary Tract Symptoms in Males with Benign Prostate Hyperplasia (The Iraqi Experience)
}

\author{
Nibbras I. AL-Hamdani* \\ Saad D. Daraji ** \\ Ali W. Zeki****
}

\author{
FICMS \\ FICMS, FABU, FEBU \\ FICMS
}

\begin{abstract}
:
Fac Med Baghdad 2015;Vol.57, No.2 Received: Dec,2014 Accepted: Mar,2015

Background: The response of overactive bladder (OAB) symptoms seen in men with Lower urinary tract symptoms/Benign prostate hyperplasia (LUTS/BPH) raises the possibility that a combination of $\alpha$-adrenergic blocker therapy with anticholinergic therapy could both reduce the risk of retention or deteriorating bladder function and also add to the treatment of the remaining obstructive symptoms of LUTS/BPH.

Objective: Is to investigate the efficacy and tolerability of $5 \mathrm{mg}$ solifenacin in the treatment of lower urinary tract symptoms in patients with benign prostatic hyperplasia in combination with an alpha-blocker.

Patients and methods: This is a prospective study of 29 patients with benign prostatic hyperplasia already on alpha-blockers, given solifenacin $5 \mathrm{mg}$ once daily. International prostate symptom score (IPSS), patient micturition diaries, quality of life index (QOL), post-void residual urine (PVR) and maximum flow rate (Qmax) and urodynamic findings were recorded before and after three months of therapy. Adverse events were documented.

Results: At baseline, the total IPSS was $15.3+5.7$ that decreased to $10.8+5.3$ (net change -4.5 , P value $<0.03$ ). Although the mean IPSS for voiding symptoms was not significant, significant change was noted in the storage symptoms (from $8.4+2.4$ to $5.1+2.5 \mathrm{P}$ value $<0.001$ ). The quality of life index was significantly improved for the patients enrolled from $4.4+1.4$ to $2.8+1.3$. The maximum flow rate increased from $11.6+5.7$ to $14.3+6.1$ with a net change of $+2.7 \mathrm{ml} / \mathrm{sec}(\mathrm{P}$ value $<0.01) \mathrm{ml} / \mathrm{sec}$. Two patients stopped the medication because of side effects. The side effects included dry mouth (17.24\%) followed by constipation (6.90\%) then headache and blurred vision $(3.45 \%)$ for each. No urine retention developed in any patient.

Conclusions: The use of solifenacin in selected cases in the treatment of LUTS in patients with BPH is highly effective addition to alpha-blockers.

Key words: Lower urinary tract symptoms, benign prostate hyperplasia, Anticholinergic medication.
\end{abstract}

\section{Introduction:}

Benign prostatic hyperplasia (BPH) is a pathologic process that contributes to, but is not the sole cause of, lower urinary tract symptoms (LUTS) in aging men. (1). Since $\alpha$-Adrenergic monotherapy is effictive in improving voiding symptoms and to a certain extent over active bladder symptoms, it is recommended as a first-line treatment for men with benign prostate obstruction (BPO) overactive bladder

$\mathrm{OAB}$ ) symptoms. However, remaining $\mathrm{OAB}$ are sometimes experienced, and such symptoms continuously impair quality of life (QOL). (2). Storage symptoms are currently largely encompassed by the term overactive bladder (OAB)

*Consultant Urologist, Surgical specialties hospital, Medical city complex.

**Assistant professor, College of medicine, University of Baghdad.

***Senior Lecturer, College of medicine, University of tikrit

Email:Saaduro@yahoo.com syndrome, which is defined as urgency, frequency, nocturia, and urge incontinence, which is believed to be correlated with underlying detrusor overactivity. These symptoms tend to be more bothersome than voiding symptoms, especially if they are associated with incontinence (3). The development, validation, translation with cultural and linguistic validation of the standardized, self-administered seven-item American Urological Association (AUA) Symptom Index (AUASI), also known as the International Prostate Symptom Score [IPSS] has been a pivotal event in the clinical research of Lower urinary tract symptoms and benign prostate hyperplasia (LUTS and BPH) (4). The IPSS is a helpful tool both in the clinical management of men with lower urinary tract symptoms and in research studies regarding the medical and surgical treatment of men with voiding dysfunction(5). Literature review strongly supports the use of antimuscarinic drugs in the treatment of $\mathrm{OAB}$ 
symptoms. They are well tolerated, but there is minimal available evidence on the long-term outcome of medical therapy of mixed $\mathrm{OAB}$ and Bladder outlet obstruction (BOO) due to benign prostate hyperplasia (BPH). The shortterm data suggest that a combination of antimuscarinic and $\alpha$-adrenergic blocker therapy is safe with minimal risk of retention or acute urinary retention (AUR) in carefully selected men. Men with significant obstruction and large, persistent residual urine volumes should be considered for surgical therapy rather than the addition of antimuscarinic agents(6). According to treatment recommendations proposed by the 6th International Consultation on New Developments in Prostate Cancer and Prostate Diseases (7), $\alpha$-blocker and anticholinergic combination therapy is recommended as a first line treatment for men with coexisting bladder outlet obstruction (BOO)OAB symptoms. However, when we consider the promising efficacy of $\alpha$ - blockers on OAB symptoms in men with BPO and adverse events as well as increased medical cost of anticholinergic agents, the add-on of anticholinergic agent following $\alpha$-blocker monotherapy seems to be clinically practical and acceptable(8). Solifenacin is a tertiary amine and well absorbed from the gastrointestinal tract (absolute bioavailability $90 \%$ ). The mean terminal half-life is 45 to 68 hours (9). It undergoes hepatic metabolism involving the cytochrome P450 enzyme system (CYP3A4). Solifenacin has a modest selectivity for M3 over M2 receptors and a marginal selectivity over M1 receptors (10). Therapeutically effective doses of solifenacin do not increase heart rate or blood pressure. Solifenacin has a well-documented effect in over active bladder/Detrusor over activity (OAB/DO), and the adverse event profile seems acceptable (11).

\section{Aim of This study:}

To determine the efficacy and tolerability of $5 \mathrm{mg}$ solifenacin for the treatment of lower urinary tract symptoms of BPH patients in addition to alpha-blockers.

\section{Patients and Methods:}

This is a prospective study conducted in the Urology Department at the Surgical Specialties Hospital of Baghdad Medical City complex for 28 months (from 1st March 2011 to the end of June 2013). Twenty-nine Patients with benign prostatic hypertrophy on alpha-blockers therapy complaining of lower urinary tract symptoms were enrolled. The inclusion criteria were male patients over 50 years of age, proved to have prostate enlargement documented by abdominalpelvic ultrasonography or Trans-rectal ultrasound (TRUS) with LUTS despite alpha blocker therapy for four weeks. Exclusion criteria included large post void residual urine over $100 \mathrm{ml}$, previous prostate surgery, previous treatment with 5 alpha reductase therapy, PSA more than $10 \mathrm{ng} / \mathrm{ml}$, and lower urinary tract disorders. In addition (Diabetes mellitus, anatomic disorders), Major cardiac insults: (heart failure, ischemic heart disease), neurogenic bladder dysfunction (excluded by history and examination), Tumor of prostate and bladder (excluded by Digital rectal examination, PSA and urine cytology), or infection (urinalysis with culture and sensitivity). The patients who were enrolled in this study took $5 \mathrm{mg}$ of a solifenacin treatment once a day for three months, The dose was taken four weeks after starting alpha blocker therapy (tamsulocine $0.4 \mathrm{mg}$ ); International prostatic symptom score (IPSS), patient micturition diaries, quality of life index (QOL), and post-void residual urine (PVR) were recorded by the interviewer before the addition of solifenacin therapy and after three months of therapy. Urodynamic study was done before starting the medication to confirm the presence of overactive bladder contractions. Overactive bladder is defined as the development of a detrusor contraction exceeding $15 \mathrm{~cm} \mathrm{H} 2 \mathrm{O}$ at a bladder volume less than $300 \mathrm{ml}$. Maximum flow rate (Qmax) was measured before starting the medication and after 3 months of therapy. A change in the type and dose of alpha-blocker was not allowed while the study period besides no other drugs was allowed to be added. If the patient experienced adverse events, they were recorded. Statistical analysis was used by SPSS software. A p value of less than 0.05 was considered significant. End point values after three months of therapy was compared to the baseline values by ( $t$ test).

\section{Results:}

Patient Population: Out of 36 patients, 29 patients completed the three months period of the study and submitted to the efficacy analysis because five patients failed to attend for follow up and two patients stopped the medication because of side effects. The mean age of the patients was $61 \pm 8$ years. The mean PSA for all enrolled patients (29) was $2.8 \mathrm{ng} / \mathrm{ml}$. Of the 29 patients, 13 patients $(44.8 \%)$ had an overactive bladder. The mean duration of previous failed alpha-blockers was 4.5 months. The alpha-blockers used were: alfuzosin 17 patients and tamsulosin 12 patients.

Efficacy Analysis: At baseline, the total IPSS was $15.3 \pm 5.7$ that decreased to $10.8+5.3$ (net change $-4.5, \mathrm{P}$ value $<0.03$ ). Most of the improvement in the IPSS parameters occurred after 4 weeks of commencing the solifenacin therapy (net change of -3.2). Significant change was noted in the storage symptoms (Table 1). The frequency, urgency and nocturia $(3.0 \pm 1.2,3.1 \pm 1.3$, and $2.8 \pm 1.2$ respectively) decreased significantly to $2.1 \pm 1.0,1.4 \pm 1.3$, and $1.6 \pm 1.1$ respectively ( $\mathrm{P}$ value $<0.001$ ). Effect on Voiding symptoms was not significant. Incomplete emptying $(2.2 \pm 1.5)$, weak stream (1.9 \pm 1.4$)$, and straining $(1.3 \pm 1.2)$ have changed to 
$(1.4 \pm 1.2,1.8 \pm 1.3$, and $1.2 \pm 1.1)$ respectively. A slight rise in intermittency score was noted from $(1.6 \pm 1.4)$ to $(1.6 \pm 1.5)$. IPSS voiding symptoms change was $(-1.0)$ (P value $>0.1)$. The quality of life index QOL (Table 1) was significantly improved in the patients enrolled from $4.4 \pm 1.4$ to $2.8 \pm 1.3$ with a $P$ value of $<0.001$.

Table (1): changes in the mean of parameters of the IPSS and quality of life index before and after 4 weeks and 12 weeks of solifenacin treatment.

\begin{tabular}{|c|c|c|c|c|}
\hline Parameter & $\begin{array}{c}\text { Before } \\
\text { Treatment }\end{array}$ & $\begin{array}{c}\text { After } \\
\text { 4Weeks }\end{array}$ & $\begin{array}{c}\text { After } \\
12 \text { weeks }\end{array}$ & P value \\
\hline Incomplete emptying & $2.2 \pm 1.5$ & $1.8 \pm 1.3$ & $1.4 \pm 1.2$ & $<0.01$ \\
\hline Frequency & $3.0 \pm 1.2$ & $2.4 \pm 1.2$ & $2.1 \pm 1.0$ & $<0.01$ \\
\hline Intermittency & $1.6 \pm 1.4$ & $1.6 \pm 1.4$ & $1.6 \pm 1.5$ & $>0.05$ \\
\hline Urgency & $3.1 \pm 1.3$ & $2.5 \pm 1.1$ & $1.4 \pm 1.3$ & $<0.001$ \\
\hline Weak stream & $1.9 \pm 1.4$ & $1.9 \pm 1.2$ & $1.8 \pm 1.3$ & $>0.05$ \\
\hline Straining & $1.3 \pm 1.2$ & $1.3 \pm 1.1$ & $1.1 \pm 1.1$ & $>0.05$ \\
\hline Nocturia & $2.8 \pm 1.2$ & $2.0 \pm 1.3$ & $1.6 \pm 1.1$ & $<0.001$ \\
\hline IPSS storage symptoms & $8.4 \pm 2.4$ & $6.2 \pm 2.3$ & $5.1 \pm 2.5$ & $<0.001$ \\
\hline IPSS voiding symptoms & $5.9 \pm 2.5$ & $5.7 \pm 2.5$ & $4.9 \pm 2.8$ & $>0.1$ \\
\hline IPSS total score & $15.3 \pm 5.7$ & $12.1 \pm 5.0$ & $10.8 \pm 5.3$ & $<0.03$ \\
\hline QOL index & $4.4 \pm 1.4$ & $3.3 \pm 1.5$ & $2.8 \pm 1.3$ & $<0.001$ \\
\hline
\end{tabular}

Total IPSS improvement for patients confirmed to have overactive bladder and those without bladder over activity was not significant. Total IPSS for patient with overactive bladder changed from $15.5 \pm 4.6$ to $11.6 \pm 6.4$ ( $\mathrm{P}$ value $>0.05$ ), while patients without overactive bladder changed from $15.6 \pm 5.3$ to $11.5 \pm 5.8$ ( $\mathrm{P}$ value $>0.05)$. (Figure 1$)$.

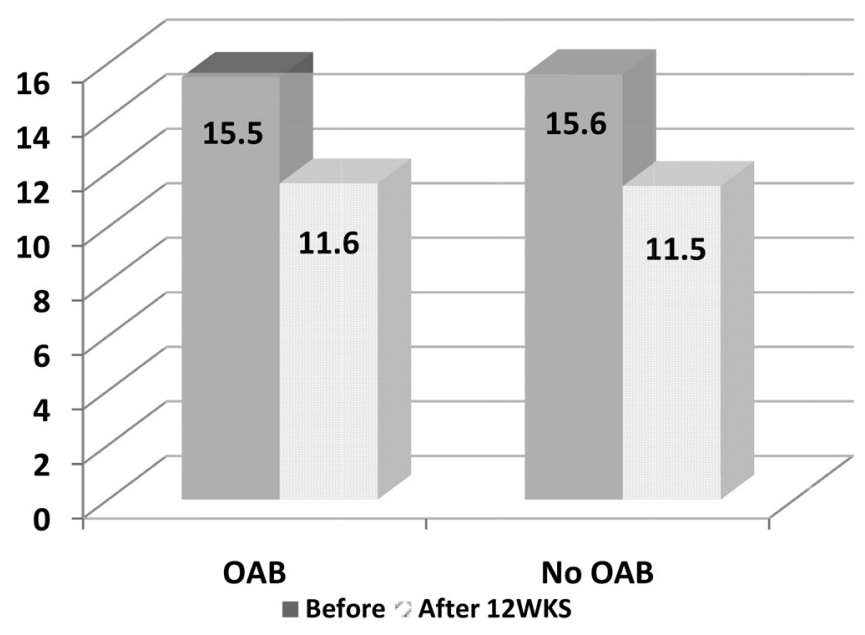

Fig (1): Mean change in IPSS for the patients with and without overactive bladder before and after Solifenacin therapy
Regarding post residual urine (Figure 2), a slight rise in the residual urine was noted (from $25.4 \pm 34.3$ to $26.6 \pm 30.2$ ) which was statistically not significant $(\mathrm{P}$ value $>0.05)$. Maximum flow rate Qmax (Figure 3) increased from $11.6 \pm 5.7$ to $14.3 \pm 6.1$ with a net change of $\pm 2.7 \mathrm{~m}$ (P value $<0.01)$.

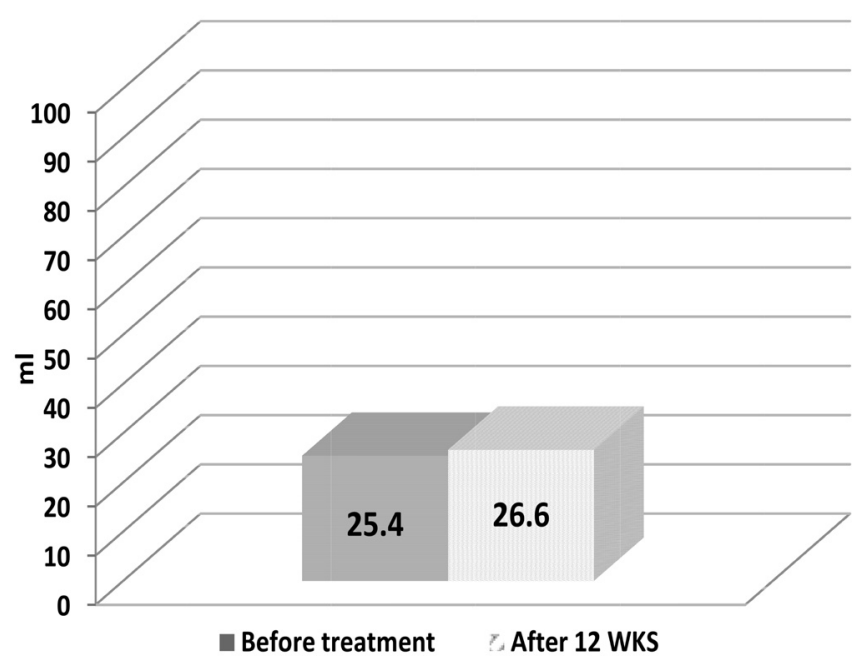

Fig( 2 ): the mean change of post residual urine before and after 12 Weeks of solifenacin treatment

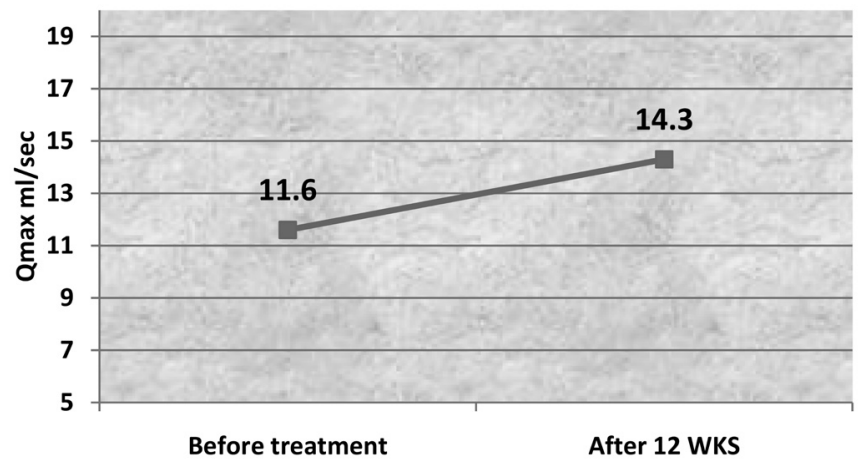

Fig( 3 ): The mean change of Qmax before and after 12 weeks of solifenacin treatment.

Safety Analysis: Of the 31 patients submitted to the safety analysis( 29 patients completed the study plus 2 patients stopped the medication for side effects), 9 sideeffects (Fig4) developed in 6 patients $(19.35 \%)$. Dry mouth was the most common adverse effect that developed in 5 patients (17.24\%) followed by constipation in 2 patients $(6.90 \%)$. Headache and blurred vision each developed in one patient (3.45\%). No urine retention developed in any patient. 


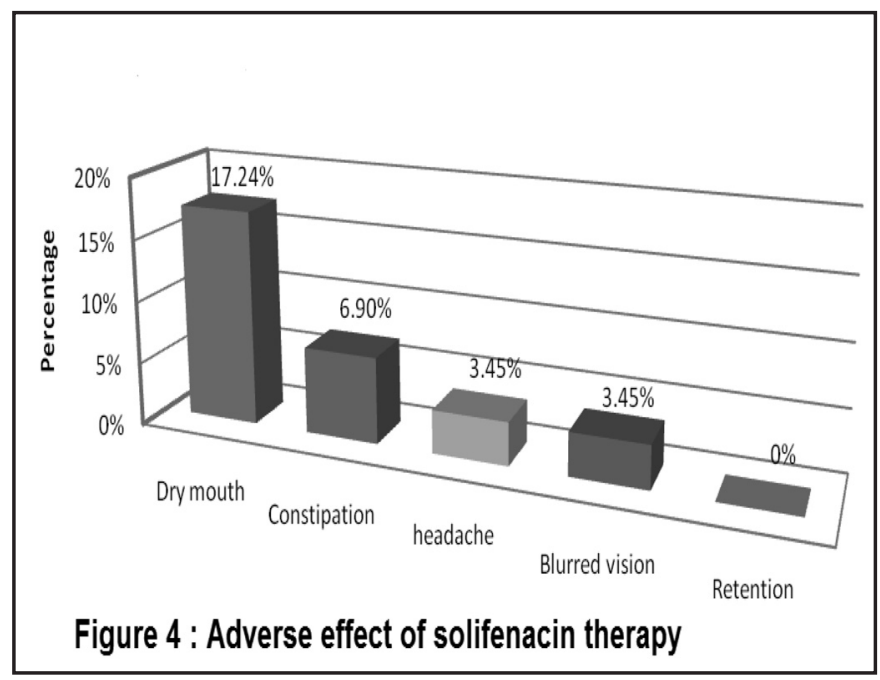

\section{Discussion:}

Benign prostatic hyperplasia $(\mathrm{BPH})$ is a pathologic process that contributes to, but is not the sole cause of lower urinary tract symptoms (LUTS) in aging men (1). LUTS had adverse effects on health related quality of life, including interference with daily activities and decreased psychological well-being, which worsen with symptom severity. LUTS include overactive bladder (OAB) symptoms, e.g. frequency, urgency, and incontinence, and voiding (or obstructive) symptoms, e.g. dribbling, hesitancy, a weak stream, and incomplete emptying (12). Thus, controlling $\mathrm{OAB}$ symptoms without aggravating voiding symptoms has become an important therapeutic goal in the management of BPH induced LUTS. $\alpha$-adrenergic receptor antagonists facilitate urine release in conditions of functionally increased urethral resistance, such as benign prostatic hyperplasia. (13). Even if it is well known that $\alpha 1$ AR antagonists can ameliorate lower urinary tract symptoms (LUTS) in men with benign prostatic enlargement there are no controlled clinical trials showing that they are an effective alternative in the treatment of $\mathrm{OAB}$ in this patient category $(14,15)$. Persisting storage symptoms not responding to $\alpha 1$ blockers are frequently observed in a clinical setting. In the subjects evaluated in our study, despite of administration of $\alpha$-blocker, the IPSS, and QOL index were 15.3 and 4.4, respectively. The IPSS voiding symptoms seemed to be well controlled by $\alpha$-blocker monotherapy. On the other hand, the IPSS storage symptom score remained high. Thus, additional treatment is mandatory for BPO/LUTS patients with persisting $\mathrm{OAB}$ symptoms to improve their QOL. Remaining OAB symptoms are mainly caused by detrusor over activity rather than BPO. (16). There are several mechanisms to explain the highly frequent association of bladder over activity with BPH/LUTS such as denervation hypersensitivity, modulated detrusor properties, increased release of urothelial neurotransmitters, and increased afferent stimulation from the urethra (17). Since anticholinergic agents contribute to improving $\mathrm{OAB}$ symptoms through the blockade of muscarinic receptors on the smooth muscle, urothelium, and afferent nerves, they may be effective to control remaining OAB symptoms after $\alpha 1$-blockers monotherapy. For patients with $\mathrm{OAB}$, antimuscarinic drugs appear to be a logical choice (18). In the present study, additional administration of solifenacin for patients with BPO/LUTS treated with $\alpha$-blocker revealed significant improvement of the remaining $\mathrm{OAB}$ symptoms without deterioration of voiding symptoms, Qmax, and PVR. The results of this study demonstrate that the solifenacin decreased OAB symptoms with storage and voiding symptoms in men with BPH in whom $\alpha$-blocker therapy failed to control these symptoms. The prevalence estimates of BOO in men with LUTS have approached $70 \%$. Furthermore, the prevalence of DO in men with BPH/LUTS has been estimated to be between $40 \%$ and $70 \%$.(19). The current results demonstrate that solifenacin was effective for male LUTS and suggested that expensive cystometric and urodynamics diagnostic techniques used to confirm DO and BOO may not be necessary to treat LUTS effectively. Combinations therapies using anticholinergics and $\alpha$-blockers have also demonstrated promise for symptomatic BOO and DO in some male populations. $(20,21)$. Although the reasons for the failed efficacy of $\alpha$-blockers in this population are not well established, it is possible that some patients had idiopathic $\mathrm{OAB}$ in the absence of BOO. Because $\alpha$-blockers may not have direct effects on detrusor contractility, the efficacy of oxybutynin treatment in these men may be attributable only to increased detrusor stability. Decreased detrusor contractions may increase bladder volume at voiding, leading to the observed improvements in hesitancy and intermittency. In addition, neither acute urinary retention nor severe adverse events were observed during the study period (22). The incidence of adverse events was low and urinary retention did not occur in any solifenacin treated men. The increases in Qmax observed with solifenacin treatment further support a low risk of urinary retention. These results are consistent with previous findings in men with $\mathrm{BPH}$ and $\mathrm{BOO}$ that suggest the inhibitory effect of antimuscarinic agents on detrusor muscle contraction is unlikely to aggravate voiding difficulties in men with $\mathrm{OAB}$ symptoms and possible BOO. There are several studies that investigated the add-on effects of anticholinergic 
agents after $\alpha 1$-blockers monotherapy. Most of the studies demonstrated similar results that the IPSS, QOL index, the IPSS storage symptoms, and OABSS were improved and the IPSS voiding symptoms remained unchanged by add-on of anticholinergic agents. No worsening of Qmax and PVR was observed except in one report. In addition, no studies reported development of acute urinary retention $(23,24,25,26)$. Kaplan et al. Reported the efficacy and tolerability of solifenacin add-onto men with residual urgency and frequency (mean urinary frequency $\geq 8$ times per 24 hours including $\geq 1$ urgency episode per 24 hours in a bladder diary) after $0.4 \mathrm{mg} /$ day of tamsulosin for 4 or more weeks. A total of 398 men were randomized to 12 weeks of solifenacin $5 \mathrm{mg}+$ tamsulosin or placebo + tamsulosin. Although there were no significant differences in reductions of urinary frequency per 24 hours $(-1.05$ versus $-0.67, \mathrm{P}=$ $.135)$ and the IPSS storage symptom score $(-2.80$ versus $-2.33, \mathrm{P}=.074$ ) between the 2 groups, urgency episode per 24hours was significantly reduced in the group to addof solifenacin $(-2.16$ versus $-1.10, \mathrm{P}<.001)$. Urinary retention was reported in seven patients $(3 \%)$ and required catheterization on solifenacin + tamsulosin whereas none was reported on placebo + tamsulosin. Thus, they concluded that solifenacin + tamsulosin was well tolerated although closer supervision may be required for men with severe BOO. (27). The present study has its limitations because of the small number of patients. However, we are not aware of a similar study in Iraq. The quality of life index QOL and other parameters were significantly improved in agreement with international studies. We do recommend the addition of solifenacin to alpha-blockers in the treatment of LUTS in patients with $\mathrm{BPH}$.

\section{Author Contribution:}

Nibbras I. AL-Hamdani: Super Vision

Saad D. Daraji: Super Vision, writing, statistics and Discussion

Ali W. Zeki: Data Collection

\section{References:}

1- Roehrborn. Pathology of benign prostatic hyperplasia. International journal of impotence research (2008), 20, S11S18; doi:10.1038/ijir.2008.55.(IVSL).

2- Naoya Masumori,1 Taiji Tsukamoto,1 Masahiro Yanase etal. The Add-On Effect of Solifenacin for Patients with Remaining Overactive Bladder after Treatment with Tamsulosin for Lower Urinary Tract Symptoms Suggestive of Benign Prostatic Obstruction. Advance in Urology Volume 2010 (2010), Article ID 205251, 5 pages.(IVSL).
3- Christopher R.etal. Lower Urinary Tract Symptoms Revisited: A Broader

Clinical Perspective. european urology 54 ( 2008 ) 563569.

4- Barry MJ, Fowler Jr FJ, et al: The American Urological Association symptom index for benign prostatic hyperplasia. The Measurement Committee of the American Urological Association. J Urol 1992; 148(5):1549-1557.discussion 1564.

5- Barry MJ, Fowler Jr FJ, et al: Correlation of the American Urological Association symptom index with selfadministered versions of the Madsen-Iversen, Boyarsky and Maine Medical Assessment Program symptom indexes. Measurement Committee of the American Urological Association. J Urol 1992; 148(5):1558-1563.discussion 1564.

6- Finney SM, Andersson KE, Gillespie JI, Stewart LH: Antimuscarinic drugs in detrusor overactivity and the overactive bladder syndrome: motor or sensory actions? BJU Int 2006; 98(3):503-507.

7- J. McConnell, P. Abrams, S. Khoury, et al., "6th International Consultation on New Developments in Prostate Cancer and Prostate Diseases. Recommendations of the international scientific committee: evaluation and treatment of lower urinary tract symptoms (LUTS) in old men, " in Male Lower Urinary Tract Dysfunction Evaluation and Management, J. McConnell, Ed., pp. 387-401, France, 21st edition, 2006.(IVSL).

8- C. Chapple, S. Herschorn, P. Abrams, F. Sun, M. Brodsky, and Z. Guan, "Tolterodine treatment improves storage symptoms suggestive of overactive bladder in men treated with a-blockers," European Urology, vol. 56, no. 3, pp. 534-543, 2009.

9- Kuipers ME, Krauwinkel WJ, Mulder H, et al: Solifenacin demonstrates high absolute bioavailability in healthy men. Drugs R D 2004; 5(2):73-81.

10- Ikeda K, Kobayashi S, Susuki M, et al: M(3) receptor antagonism by the novel antimuscarinic agent solifenacin in the urinary bladder and salivary gland. Naunyn Schmiedebergs Arch Pharmacol 2002; 366:97-103.

11-O. Yamaguchi, E. Marui, and E. Marui, "Randomized, double-blind, placebo-and propiverine-controlled trial of the once-daily antimuscarinic agent solifenacin in Japanese patients with overactive bladder," BJU International, vol. 100, no. 3, pp. 579-587, 2007.

12-Abdel-Rahme'ne Azzouzi, Marc Fourmarier ,Francois $D$. , et al . Other therapies for BPH patients: desmopressin, anti-cholinergic, anti-inflammatory drugs, and botulinum toxin. World J Urol (2006) 24: 383-388 DOI 10.1007/ 
s00345-006-0095-x.

13-Ramsay JW, Scott GI, Whitfield HN: A double-blind controlled trial of a new alpha-1 blocking drug in the treatment of bladder outflow obstruction. Br J Urol 1985; 57(6):657-659.

14- McNeill SA, Hargreave TB, Roehrborn CG: Alfuzosin $10 \mathrm{mg}$ once daily in the management of acute urinary retention: results of a double-blind placebo-controlled study. Urology 2005; 65(1):83-89.discussion 89-90.

15-Chapple CR, Baert L, Thind P, et al: Tamsulosin $0.4 \mathrm{mg}$ once daily: tolerability in older and younger patients with lower urinary tract symptoms suggestive of benign prostatic obstruction (symptomatic BPH). The European Tamsulosin Study Group. Eur Urol 1997; 32(4):462-470.(IVSL).

16- Eckhardt MD, van Venrooij GE, Boon TA. Interactions between prostate volume, filling cystometric estimated parameters, and data from pressure-flow studies in 565 men with lower urinary tract symptoms suggestive of benign prostatic hyperplasia. Neurourol Urodyn. 2001; 20: 579.

17- Homma Y, Araki I, Igawa Y et al., "Clinical guideline for male lower urinary tract symptoms," International Journal of Urology, vol. 16, pp. 775-790, 2009.

18- Chapple CR, Cardozo L, Steers WD, Govier FE: Solifenacin significantly improves all symptoms of overactive bladder syndrome. Int J Clin Pract 2006; 60(8):959-966.

19- Knutson T, Schafer W, Fall M, Pettersson S, Dahlstrand C. Can urodynamic assessment of outflow obstruction predict outcome from watchful waiting? - A four year follow-up study. Scand J Urol Nephrol. 2001; 35: 463.

20- Lee JY, Kim HW, Lee SJ, Koh JS, Suh HJ, Chancellor $M B$. Comparison of doxazosin with or without tolterodine in men with symptomatic bladder outlet obstruction and an overactive bladder. BJU Int. 2004; 94: 817.

21-Athanasopoulos A, Gyftopoulos K, Giannitsas K, Fisfis $J$, Perimenis P, Barbalias G. Combination treatment with an $\alpha$-blocker plus an anticholinergic for bladder outlet obstruction: a prospective, randomized, controlled study. J Urol. 2003; 169: 2253.

22-Sugiyama T, Shimizu N, Yoshioka N, Hanai T, Matsumoto $S$, Uemura T, "The treatment of overactive bladder symptoms related to benign prostatic hyperplasia with an anticholineric agents," Neurogenic Bladder Society, vol. 15, pp. 191-197, 2004.

23- A. Tsujimura, T. Takao, K. Uchida, et al., "Clinical efficacy of tolterodine for patients with overactive bladder after in sufficient efficacy by monotherapy with aladrenoceptor antagonist, " Japanese Journal of Urological Surgery, vol. 100, pp. 689-692, 2009.

24-Y. Nishino, M. Kikuchi, T. Masue, K. Miwa, T. Deguchi, and Y. Moriyama, "Combination therapy with an $\alpha 1$ adrenergic antagonist and an anti-cholinergic agent for patients with prostatic hypertrophy associated with an overactive bladder : combined effects of silodosin and imidafenacin," Japanese Journal of Clinical Urology, vol. 63, no. 9, pp. 719-726, 2009. View at Scopus

25-Y. Sumino, Y. Fujita, M. Yamasaki, et al., "Evaluation of imidafenacin in patients with overactive bladder due to benign prostatic hyperplasia," Japanese Journal of Urological Surgery, vol. 23, pp. 39-43, 2010.

26- O. Nishizawa, O. Yamaguchi, M. Yakeda, and $O$. Yokoyama, "Trial of combination treatment with an alpha-blocker plus anticholinergic for BPH with OAB," Neurogenic Bladder Society, vol. 20, p. 288, 2009.

27- S. A. Kaplan, K. McCammon, R. Fincher, A. Fakhoury, and $W$. He, "Safety and tolerability of solifenacin add-on therapy to $\alpha$-blocker treated men with residual urgency and frequency, "Journal of Urology, vol. 182, no. 6, pp. 28252830, 2009. 